E3S Web of Conferences 1, 04003 (2013)

DOI: $10.1051 / \mathrm{e} 3$ sconf/20130104003

(C) Owned by the authors, published by EDP Sciences, 2013

\title{
Relationship between Magnetic Susceptibility and Heavy Metals Concentration in Polluted Soils of Lenjanat Region, Isfahan
}

\author{
M. H. Salehi ${ }^{1}$, SH. Jorkesh ${ }^{2}$ and R. Mohajer ${ }^{3}$ \\ ${ }^{1}$ Associate Prof., Soil Sci. Dept., College of Agriculture, Shahrekord University, Shahrekord, Iran, \\ mehsalehi@yahoo.com \\ ${ }^{2}$ MS student, Soil Sci. Dept., College of Agriculture, Shahrekord University, Shahrekord, Iran, \\ shahrbanooj@yahoo.com \\ ${ }^{3}$ Ph.D. Student, Soil Science Dept., College of Agriculture, Shahrekord University and Scholarship of Payame Noor \\ University, Shahrekord, Iran, r_mohajer2000@yahoo.com
}

\begin{abstract}
This study analyzed the relationship between soil magnetic susceptibility and the content of $\mathrm{Cd}$, $\mathrm{Cu}, \mathrm{Ni}$, and $\mathrm{Fe}$ on 233 samples from polluted soils of Lenjanat Region in the Isfahan. The aim was to investigate the suitability of such measurements for indicating heavy metal pollution. Heavy metal contents were determined after extraction with nitric acid. Basic soil characteristics were determined using common methods. Geochemical analysis of soil samples showed close correlation between $\mathrm{Cd}, \mathrm{Ni}$ and $\mathrm{Fe}$. $\mathrm{Cd}$ concentration was the highest of all the elements studied. The correlation between the analyzed metals and magnetic susceptibility are positive and significant for $\mathrm{Fe}$ and $\mathrm{Cu}$. Results suggests that magnetic susceptibility can be used as a guideline to find contaminated urban areas with $\mathrm{Fe}$ and $\mathrm{Cu}$ in this region.
\end{abstract}

Key words: Heavy metals, Magnetic Susceptibility, Soil Pollution

\section{Introduction}

Contamination of soils with heavy metals has usually occurred in areas of mining, processing, and smelting of metals ores. Sims (1986) established the toxicity and mobility of heavy metals in soil is not controlled by the total concentration only, but is depends also on metal properties (e.g. binding state) and environmental factors (e.g. soil $\mathrm{pH}$, redox condition or organic matter content).

Strzyszcz (1993) and Petrovsky et al. (2001) reported chemical and geochemical methods are used for monitoring of polluted areas most often. This approach requires a great number of chemical analyses of many soil sample, which is time consuming and expensive. For these reasons the environmental magnetic methods to delineate the areas of polluted soils and to assess the degree of pollution have been investigated.

Cornell (1991) established various mechanisms for the coexistence of heavy metals with iron oxides in soils in have been identified. Where iron oxide particles are discharged from industrial processes, associated heavy metals can either be incorporated into their spinal structure, or be adsorbed to their surface. In a case study France, Lecoanet et al. (2003) established that bi-plots of magnetic susceptibility vs. ARM/SARM helped to distinguish the different sources of iron-oxides. Various mechanisms for the correlation of heavy metals with ironoxides in soils have been identified, especially adsorption and incorporation. Petrovsky and Ellwood (1999) and Wehland et al. (2002) found that the individual contribution depend strongly on the source of contamination, local soil geology and geochemistry.

Heller et al. (1991) and Bityukova et al. (1999) reported close relationships of magnetic susceptibility with heavy metal contamination in soil has been proven by combined analyses of chemical and magnetic data. Magnetic susceptibility thus provides an indicator of heavy metal contamination of soils.

Hoffmann et al. (1999) successfully measured road traffic pollution by evaluating the spatial distribution of magnetic susceptibility in the nearby soils. Only a fraction of the pollutants was airborne. The strongest enhancement was found at the road' s verge, indicating washed-down abrasion particles. For a confined research 
area in Bratislava, Slovakia, Durza et al. (1993) found some correlation of magnetic susceptibility with the total concentration of heavy metals but not with individual elements. The aim of this study was to examine the relationships between measurement of soil magnetic susceptibility and the content of some of heavy metals in soil.

\section{Materials and Methods}

The present study is focused on Lenjanat Region, Isfahan, where intensive agriculture surrounded by industrial activities like steel company, cement factory and Bama Lead Mine.

Twenty hundred and twenty topsoil samples from 0 $10 \mathrm{~cm}$ depth of the three soil map units (60 samples from each) were randomly collected. The magnetic susceptibility values were recorded with a Bartington MS2 dual frequency sensor. Soil samples were air dried, crushed, and passed through $2 \mathrm{~mm}$ sieves prior to chemical analysis. Basic soil characteristics were determined using common methods. Metals $(\mathrm{Cd}, \mathrm{Ni}, \mathrm{Cu}$, and $\mathrm{Fe}$ ) were extracted by nitric acid and then their concentration was measured by flame atomic absorption spectrometry under standard condition.

\section{Result and Discussion}

The mean, minimum and maximum values and standard deviation of heavy metals content are shown in Table 1 . The concentration of $\mathrm{Cd}$ in $43.8 \%$ of the samples was higher than admissible limit according to Swiss thresholds. Amini (2005) believed that land use and regional geology affect high $\mathrm{Cd}$ concentration in Isfahan.

In spite of high concentration of other studied elements, their limits were lower than threshold values. However, high $\mathrm{Fe}$ concentration could be due to the anthropogenic resources such as steel- making factories in the area. The long-term application of fertilizers may be another source for accumulation of heavy metals in the agricultural lands.

Table 1. Mean, minimum and maximum values and standard deviation of heavy metals content.

\begin{tabular}{|c|c|c|c|c|}
\hline & $\mathrm{Cd}$ & $\mathrm{Fe}$ & $\mathrm{Ni}$ & $\mathrm{Cu}$ \\
\hline Mean & 1.11 & 10733.83 & 31.56 & 9.97 \\
\hline Max & 7.44 & 17623.58 & 47.02 & 31.52 \\
\hline Min & 0.06 & 4340 & 15.75 & 4.97 \\
\hline $\begin{array}{l}\text { Standard } \\
\text { deviation }\end{array}$ & 0.85 & 2483.90 & 6.09 & 2.19 \\
\hline
\end{tabular}

Table 2. Correlation coefficients between heavy metal contents and magnetic parameters $(\chi) \times 10^{-8} \mathrm{SI}$.

*,** indicates significant relationship at the significance

\begin{tabular}{r|rrrrr}
\hline & $\chi$ & $\mathrm{Cd}$ & $\mathrm{Fe}$ & $\mathrm{Ni}$ & $\mathrm{Cu}$ \\
\hline$\chi$ & 1 & & & & \\
$\mathrm{Cd}$ & -0.06 & 1 & & & \\
$\mathrm{Fe}$ & $\mathbf{0 . 3 6}^{* * *}$ & $\mathbf{0 . 2 9}^{* * *}$ & 1 & & \\
$\mathrm{Ni}$ & $\mathbf{0 . 2 0}^{* *}$ & $\mathbf{0 . 3 5}$ & $\mathbf{0 . 8 4}^{* * *}$ & 1 & 1 \\
$\mathrm{Cu}$ & $\mathbf{0 . 2 1}^{* *}$ & -0.09 & $\mathbf{0 . 2 7}^{* *}$ & $\mathbf{0 . 3 8}^{* *}$ & \\
& & & & & \\
\hline
\end{tabular}

level 0.05 and 0.01 respectively

Close correlation between $\mathrm{Cd}, \mathrm{Ni}$ and $\mathrm{Fe}$ suggesting the same pollution source (Table 2) like steel- and cementmaking factories. The correlation between the analyzed metals and magnetic susceptibility are positive and significant for $\mathrm{Fe}$ and $\mathrm{Cu}$, and correlation between $\mathrm{Ni}$ concentration and magnetic susceptibility is negative and significant (Fig. 1 and Table 2). For Fe, the low and significant correlation with magnetic susceptibility can be attributed to the influence of anthropogenic magnetic particulate matter. This indicates magnetic susceptibility can be used as a guideline to find contaminated urban areas with $\mathrm{Fe}$ and $\mathrm{Cu}$. Kukier et al. (2003) mentioned that the correlation between magnetic susceptibility and $\mathrm{Cu}$ can be attributed to the incorporation of $\mathrm{Cu}$ in the crystalline structure of Fe mineral molecules. Negative and significant correlation between $\mathrm{Ni}$ and magnetic susceptibility may be attributed to the fact that these elements do not show an anthropogenic increase.

\section{Conclusion}

A pronounced positive and significant correlation was found in the contaminated area between the concentration of heavy metal elements $\mathrm{Fe}, \mathrm{Ni}$ and $\mathrm{Cd}$. There is no correlation with $\mathrm{Cu}$. Magnetic susceptibility show positive and significant correlation only with $\mathrm{Fe}$ and $\mathrm{Cu}$. Although positive correlation was reported in many other areas, there is no correlation between $\mathrm{Cd}$ content and magnetic susceptibility in Lenjanat region. It seems that magnetic susceptibility can be used as a guideline to find contaminated urban areas with high $\mathrm{Fe}$ and $\mathrm{Cu}$ values. Preparing the maps of magnetic susceptibility and their comparison with heavy metal maps could give a better insight for ability of this method in environmental studies. Studying these relationships in aerosols is also recommended. 

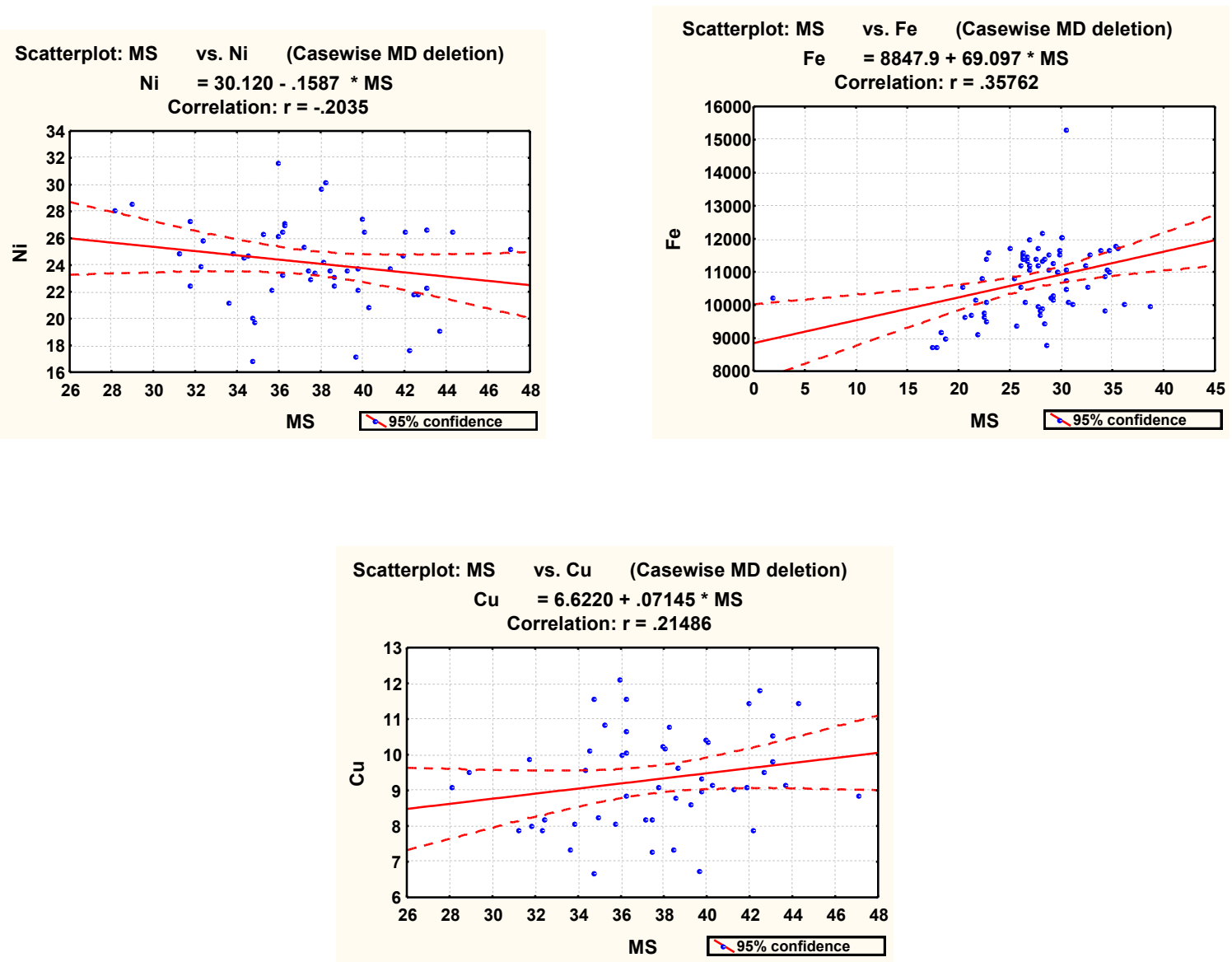

Fig. 1. The relationship between heavy metal concentration and magnetic susceptibility

\section{References}

Amini M. Modeling the accumulation heavy metal in agricultural ecosystems and evaluation of its uncertainty in Isfahan. Ph.D. thesis soil. College of Agriculture. Isfahan. Isfahan Technology University.

Cornell RM. Simultaneous incorporation of $\mathrm{Mn}$, $\mathrm{Ni}$ and $\mathrm{Co}$ in the goethite structure. Clay Miner. 1991; 26:427-430.

Bityukova L, Scohlger R, Birke M. Magnetic susceptibility as indicator of environmental pollution of sols in Tallin. Phys. Chem. Earth 1999. 24:829-835.

Durza O, Gregor T, Anatalova S. The effect of the Heavy metals soil contamination on the magnetic susceptibility. Acta Univertitatis Carolinae Geologica 1993; 37:135-143.

Heller F, Strzyszcz Z, Magiera T. Magnetic record of industrial pollution in forest soils of Upper Silesia, Poland. Geophys. Res 1998; 109:17.767.

Hoffmann V, Knab M, Appel E. Magnetic susceptibility of roadside pollution. Journal of Geochemical Exploration 1999; 66: 313-326.
Kukier U, Ishak Ch F, Sumner ME, Miller WP. Composition and element solubility of magnetic and non-magnetic fly ash fractions. Environ. Poll 2003; 123:255-266.

Lecoanet H, Leveque F, Ambrosi JP. Combination of magnetic parameters: an efficient way to discriminate soil-contamination sources (South France). Environmental Pollution 2003; 122: 229134.

Petrovsky E, Ellwood BB. Magnetic monitoring of airland and water-pollution. In: Maher BA, Thompson R (Eds.), Quaternary Climates, Environments and Magnetism. Cambridge University Press, Cambridge, pp 1999; 279-322. Chap. 8.

Sims R. Contaminated surface soils in-place treatment techniques. Noyes Publ., New Jersey 1986.

Strzyszcz Z. Magnetic susceptibility of soils in the areas influenced by industrial emissions. In: Schulin R, Sesaules A, Webster R, Steiger BV. (Eds.), Soil Monitoring. Birkhauser Verlag, Besel 1993; 225269. 